\title{
Venezuela a partir de Chávez: identidad cultural y política
}

\author{
Max RÖMER PIERETTI \\ Universidad Camilo José Cela \\ mwalter@ucjc.edu
}

\begin{abstract}
Resumen:
La democracia venezolana de finales del siglo XX e inicios del siglo XXI ha estado signada por la figura de Hugo Chávez Frías. Desde que intentara un golpe de Estado contra el entonces presidente Carlos Andrés Pérez, hasta su muerte, definió la identidad cultural y política del país con su estilo particular y, sobre todo, con el uso de los medios de comunicación social como grandes configuradores del imaginario colectivo. El análisis se centra en comprender la identidad venezolana, basándose el estudio, en lo que considera el autor grandes hitos comunicativos de los 20 años del comandante Chávez en la palestra pública venezolana y universal.
\end{abstract}

Palabras clave: Comunicación; identidades culturales y políticas; revolución bolivariana; historia contemporánea de Venezuela; medios de comunicación.

\section{Venezuela from Chavez: cultural and political identities}

\begin{abstract}
:
Venezuelan democracy in the late twentieth and early twenty-first century has been marked by the figure of Hugo Chávez Frías. Since a coup attempt against then President Carlos Andrés Pérez, until his death, defined the cultural and political identity of the country with their particular style and, above all, with the use of social media as major shapers of the imaginary collective. The analysis focuses on understanding the Venezuelan identity based study in what author's considers the communicative milestones of the twenty years of Commander Chavez in Venezuela and universal public arena.
\end{abstract}

Key Words: Communication; cultural and political identities; Bolivarian Revolution; Venezuela's contemporary history; media.

\section{Referencia normalizada:}

Römer Pieretti, M. (2014): Venezuela a partir de Chávez: identidad cultural y política. Historia y Comunicación Social. Vol. 19. Núm. Especial Febrero. Págs. 55-65.

Sumario: 1. Introducción. 2. Historia reciente de Venezuela. 2.1 El último cuarto del siglo XX. 2.2. Del despertar democrático a Chávez. 2.3 Los oponentes a Chávez en 1998. 2.4 La campaña de 1998. 3. Chávez es electo presidente. 4. Identidades culturales para la identidad política del chavismo. 5. Conclusiones. 6. Referencias Bibliográficas. 


\section{Introducción}

El trabajo que se presenta es una revisión histórica-periodística de las transformaciones relativas a la identidad cultural y política de Venezuela, a partir de la aparición del teniente coronel Hugo Rafael Chávez Frías en el escenario político y social en febrero de 1992, luego del fallido golpe de Estado que encabezó contra Carlos Andrés Pérez. La pantalla de televisión, le dio, desde el punto de vista de la investigación, la palestra necesaria para poder hacerse con el poder por mecanismos democráticos en diciembre de 1998 y es, a partir de esa fecha y gracias al manejo discursivo y mediático que desarrolló el extinto presidente Chávez, además de ampararse en los valores ancestrales de las razas menos favorecidas luego de la conquista -la negra y la india, así como todos los tonos mestizos-, que logró transformar la identidad venezolana en el plano político y cultural. Una transformación que ocupa el nuevo imaginario colectivo y que, a la luz de lo estudiado, representa lo que bien podría llamarse la venezolanidad chavista.

\section{Historia reciente de Venezuela}

\subsection{El último cuarto del siglo XX}

Corría el tercer año del gobierno de Carlos Andrés Pérez. Antes, en 1989, su inauguración en el poder, fue seguida con interés por los medios de la época.

La falta de alimentos, educación, sistemas sanitarios y culturales que hoy sufren nuestros niños se transformará, con los años, en severos traumas sociales y en degradaciones difíciles de superar. Hay que tomar decisiones para vencer la crisis y no podemos equivocarnos. Ya no hay tiempo (Pérez, 1989 en Semprún, 1989: 27)

Esas palabras de Pérez en su toma de posesión el 2 de febrero de 1989 y destacadas por el diario $A B C$, hablaban de la compleja herencia que recibía, de fuertes compromisos de deuda que implicaron medidas neoliberales. La toma de decisiones políticas en materia económica rápidamente se tiñó de sangre porque el pueblo -alzándose en protesta generalizada - fue reprendido por el gobierno. Esta revuelta o reacción popular que se conoce como el 'Caracazo', ocurrió los días 27 y 29 de febrero de 1989, implicó saqueos, destrucción del algunas propiedades privadas, pero sobre todo, la pérdida del control social y político. La yesca fue el paquete neoliberal, cuya primera medida, fue incrementar los precios del combustible, tradicionalmente muy económico en el país caribeño por tratarse de un país de alta producción petrolera, lo que se revertió inmediatamente en el incremento de los precios del transporte.

Para acallar al clamor popular y como medida de represión, se sacó al ejército a la calle lo que generó fuertes enfrentamientos, heridos y muertos. Uno de esos militares que apuntó sus armas contra el pueblo fue Hugo Chávez Frías. Fueron suficientes tres años para que, junto a un grupo de militares y habiendo jurado bajo el 'Samán 
de Güere' (árbol emblemático en la lucha por la libertad puesto que cobijó al ejército libertador en el siglo XIX), emprendieran la toma de varias ciudades del país, con tan mal tino que Caracas, no pudo ser doblegada. Arrestado Chávez, aparece por vez primera en televisión, rodeado por los micrófonos de los medios de comunicación, ofrecido al país por el propio Ministerio de Comunicaciones a través de su Oficina Central de Información y allí, rindiéndose ante las cámaras, haciendo un llamado a sus correligionarios para que depusieran también sus armas, asume toda la responsabilidad del fracaso del golpe de estado y proclama que "por ahora" no se habían logrado los objetivos de transformación social que habían ideado. La imagen fue suficiente para que un país lleno de necesidades morales se volcara a idolatrar a Chávez (Chávez, 1992).

El proceso de reivindicación de Chávez se inició con lo que el propio presidente llamó 'políticas socialistas del siglo XXI', que resultaron ser parecidas a las emprendidas por Fidel Castro en Cuba. Una política que se aviene muy bien con la identidad institucional venezolana que proviene de lealtades entendidas de una manera simplista de 'quien me dé' o 'donde haya'. En la época de la independencia (primer cuatro del S. XIX) era común que parte de las familias estuviesen indistintamente del lado realista o patriótico dependiendo de esa dádiva. Es decir, "No se entiende nada de Hispanoamérica sin España y sin los procesos europeos, como tampoco se entendería nada de España sin América" (Caldevilla, 2011: 29).

Esa cultura también se refleja en una gratitud expresada en la tenencia, en un lugar de honor, en las casas más pobres, de un retrato de quien esté en la presidencia. Ese retrato va sustituyendo al anterior o simplemente está encima del anterior -al colocarse con engrudo- en las residencias populares. Es muy importante, que el retrato esté ubicado de tal forma que se pueda ver desde la calle, puesto que da sentido de reciprocidad y gratitud con quien manda.

\subsection{Del despertar democrátivo a Chávez}

El siglo XX se inicia, en materia de política en Venezuela con la muerte del general Juan Vicente Gómez en 1935. En ese mismo momento, el Congreso Nacional elige de entre las filas de los gomecistas (personeros que habían sido parte del gobierno del Gral. Gómez) al exministro de Guerra y Marina Eleazar López Contreras. Surge así la democracia en Venezuela. Una democracia que se va afianzando al hacer que el voto fuese universal, al sucederse presidentes, aunque se interrumpe esta dinámica entre 1948 y 1958 con la dictadura del también general Marcos Pérez Jiménez. A partir de 1958, la democracia venezolana se erige como un ejemplo de alternancia democrática en todo el continente latinoamericano. Una alternancia entre dos partidos políticos, Acción Democrática y COPEI, que marcó el ritmo de la vida del país y, en consecuencia unas campañas marcadas por dádivas y reciprocidades. El caldo de cultivo perfecto -cultural e ideológico- para la plataforma que el comandante Chávez quería desarrollar. 
La campaña de Chávez para las elecciones de 1998 rescató un valor que no existía en la comunicación política del bipartidismo: la lucha contra la corrupción. Chávez llevaba 6 años formándose, planificando su irrupción en el poder luego del sobreseimiento que le diera el presidente Caldera en 1994 (Caldera, 2007). Chávez es quien abandera esa imagen, ese imaginario creado por los medios de comunicación con el comandante como protagonista. Los candidatos que con él se presentan para las elecciones de 1998 no se acercan a ese "ideario" chavista.

Chávez recorrió el país sobre un camión 'tres-cincuenta'. Dese allí hacía sus arengas, se rozaba con la gente, estrechaba voluntades, hizo una vuelta al país ganándose amistades y lealtades más allá de la política de la dádiva. Su discurso convenció a muchos. Un discurso que pasaba por una revisión profunda de la constitución de 1961, por cambiarla para reivindicar al pueblo, por luchar contra la corrupción, por poner en alto el legado libertario de Bolívar y por ser además, y eso gracias a la prensa, un paladín de la justicia por haberse alzado en contra del sistema establecido, en contra de Carlos Andrés Pérez que fue, en definitiva, quien fue contra el pueblo en febrero de 1989.

El pueblo se identificó con esa sed de justicia que proponía un militar como Chávez. Desde 1989, con la aparición del general y ministro de defensa Ítalo del Valle Alliegro para adoptar el mando en pleno Caracazo, los militares se erigieron como adalides del buen hacer y del recto proceder institucional. Desde hacía tiempo los civiles buscaban la figura fuerte, un don de mando para el país. Subrayada la imagen de Chávez de entereza, la campaña fue propicia para que la gente, el pueblo y hasta los intelectuales imaginaran un país de justicia, equidad y oportunidades para todos.

\subsection{Los oponentes a Chávez en 1998}

El partido social cristiano COPEI tenía como candidata a la ex miss universo 1981 Irene Sáez. Su currículo vitae en materia política provenía de ser la primera alcaldesa de la recientemente creada Alcaldía de Chacao, un municipio de alto nivel adquisitivo en la Gran Caracas y que, desde su fundación y gestión con Sáez al frente, se había convertido en ejemplo del buen hacer gubernamental. Ese aval, sumado al carisma propio por su condición de reina de belleza, más el respaldo de uno de los bancos más importantes de Venezuela, era la plataforma de la campaña de Irene Sáez.

Acción Democrática (fundado en 1941 y el más antiguo de Venezuela) lanzó a un candidato de mucha influencia dentro de las filas del partido, pero con muy poco arrastre en materia de votantes jóvenes, Luis Alfaro Ucero. Alfaro no supo entender que la coyuntura venezolana había cambiado luego del intento de golpe de estado de 1992 y tampoco entendió que las fuerzas políticas de los partidos no tenían el empuje del pasado. No supo evaluar que el presidente Caldera había llegado al poder en 1993 con la suma de todos los partidos pequeños (Caldera rompe en 1993 con el bipartidismo al ganar las elecciones con un fenómeno político que se llamó Convergencia) y que el país lo que reclamaba era moral, ética y limpieza de gestión. 
Otro de los candidatos, Henrique Salas Römer, tenía una gestión como gobernador del estado Carabobo. Su campaña trató de relacionar su lucha por la presidencia con los idearios de la guerra de independencia, puesto que fue su estado donde se libró la batalla final en la lucha contra la corona española en 1821. La relación histórica planteada por una persona rubia -catire-, de origen norte europeo, sobre un caballo, además de sus relaciones con el empresariado carabobeño, no le granjeó el favor del pueblo que se identificaba con el teniente golpista que la prensa había fabricado.

\subsection{La campaña de 1998}

Fue una campaña muy desigual, sin sentido de comprensión del entorno por parte del aparato político tradicional, sin observancia de las condiciones y sin alianzas estratégicas con el pueblo. Se entregó, por así decirlo, al país quien los medios habían idolatrado, al soñador, a Hugo Rafael Chávez Frías.

\section{Chávez es electo presidente}

Un hombre joven gana las elecciones. El contraste con el octogenario Caldera es radical. La juventud le permite romper con lo estatuido. Su jura como presidente de la república de Venezuela la hace frente al entonces presidente Rafael Caldera Rodríguez y a Luis Alfonso Dávila García, por entonces presidente de la cámara del Senado venezolana:

Juro delante de Dios, juro delante de la Patria, juro delante de mi pueblo que sobre esta moribunda Constitución impulsaré las transformaciones democráticas necesarias para que la República nueva tenga una Carta Magna adecuada a los nuevos tiempos. Lo juro (Chávez, 1999 en Analítica, 1999).

El juramento, contrario a lo esperado, divide a la opinión pública. Considerar moribunda a la Constitución Nacional de 1961 daba pie a comprender que la Asamblea Constituyente establecería las nuevas bases del Estado venezolano, un rediseño de los poderes públicos, el instrumento institucional acorde con las necesidades de las promesas electorales de Chávez. Otros, por el contrario, consideraron que la nueva constitución sería instrumento de opresión, de persecución y mecanismo para el desbaratamiento institucional (que vendría después). Diversas voces se alzaron desde la academia, desde el mundo industrial.

El referéndum aprobatorio tuvo lugar el 16 de diciembre de 1999 y alcanzó el $71 \%$ de los votos a favor de la nueva Carta Magna. Con su constitución en la mano, Chávez emprendió un proceso de expropiación, persecución y oprobio que todavía en 2013 se sigue viviendo bajo el gobierno de Nicolás Maduro. Listar las expropiaciones no sería posible en el espacio que tiene este artículo (EFE, 2010), mas observar lo que ha significado en materia de productividad y empleo formal, así como tratar de llevar el control de los factores de producción es la forma socialista de entender por Chávez el poder. 
No se trata de un socialismo a la europea. Se trata una sovietización del Estado que, al estar amparada desde la comunicación a través de las múltiples cadenas y su programa de TV 'Aló, Ciudadano', es decir, la permanente campaña política, el pueblo chavista responde siempre con esperanza de distribución de la riqueza, así como con ilusión de cambio. Unas formas cercanas y campechanas para decirle al pueblo por medio de las pantallas que él -el presidente- está con el pueblo, con sus necesidades de justicia social entendida desde la dádiva, desde la lealtad que genera la tenencia futura, esa que sacará de la miseria.

Ante las expropiaciones el empresariado hace esfuerzos por sobrevivir. El aparato de marketing y distribución alimenticio está en manos del chavismo y, al tener ese control sobre el mercado de los alimentos, las posibilidades de maniobra de los industriales del sector se ven atadas a producir para el chavismo o desaparecer bajo la política de expropiaciones. A pesar de esta sovietización del aparato productivo, el sino económico se caracteriza por la baja productividad venezolana, de la dependencia de las exportaciones para mantener abastecido y alimentado al país, lo que hace que parte de la agenda de los medios se el tratamiento de estos temas, desabastecimiento y escasez. Para solventar, al menos mediáticamente el problema del abastecimiento de alimentos frente a la población seguidora de las políticas de Chávez, el presidente creó la red de mercados populares Mercal (Mercal, 2010). Esta se convirtió en el suplidor de alimentos de la población y, de alguna manera, en el único canal de distribución en el que se consiguen los productos que son importados por el gobierno. El resto de las cadenas de distribución privadas, ven mermados sus esfuerzos de distribución de víveres. Así, Mercal se transformó en un canal más de difusión ideológica, toda vez que se plantea el acceso a los alimentos.

La gran plataforma de distribución ideológica del chavismo adoptó el nombre de misiones. Estas responden a las muchas necesidades sociales, que en lugar de tener forma institucional o de reforzar el aparato institucional del Estado, han adoptado formas de apoyo social, económico, sanitario con una estructura propia de los criterios de dádiva-lealtad, es decir, se construye identidad institucional sobre la base de la cercanía que tenga el pueblo con las misiones y la solución que la propia misión plantee (Matheus, 2012). Esta realidad plantea la no existencia de un aparato institucional estatal que se vele por las actividades sociales, educativas, deportivas, sino que es a través de estas misiones que se personaliza la dádiva, siempre encarnada por la figura de Chávez, lo que le granjeó fuertes lealtades.

\section{Identidades culturales para la identidad polótica del chavismo}

Monsoyi propone una posición de identidad de carácter dialéctico. "La identidad es un conjunto dialéctico de especificidades -tanto objetivas como subjetivas-actuantes dentro de una sociedad" (1981: 157). Esa es la identidad que adopta el chavismo, una identidad política venezolana que se fundamenta en la dialéctica que generó Chávez 
desde el mismo momento de su juramento como presidente, al determinar una diferencia entre el pasado y el futuro para dar pie a su proyecto.

Esa dialéctica se mantiene con el gobierno de Maduro al promover desde el poder diferencias entre los venezolanos.

[...] esta nueva manera de pensar 'lo político' identifica a esta noción como una dimensión de la cultura - aquella de las luchas por imponer los propios sistemas de representación-; si esto es así, entonces intervenir políticamente en la cultura será ahora una forma de intervenir también en lo político (Maccioni, 2001 en Altez, 2003: 82).

Es evidente que la cultura e identidad de un país no tiene una solo o única expresión, la cultura de una nación se define por eso, por su multiculturalidad. Adoptamos así la posición de Hopenhayn, que propone el concepto de Estado-Nación y territorio e identidad nacional. Escribe

la relación establecida entre cultura y política queda radicalmente cuestionada en la medida que el Estado-Nación pierde su carácter de unidad político-cultural y tiende a restringirse al carácter de una unidad político-institucional con funciones regulatorias en el campo de la economía y de los conflictos entre actores sociales (2002: 1).

Una asimetría entre emisores -Chávez, Maduro y el chavismo- y los receptores -todo el pueblo venezolano-, ya que si bien el discurso del chavismo luce cercano al pueblo afecto al gobierno, no queda fuera de la ecuación el pueblo 'opositor' que ha vivido y vive con cuestionamientos a su propia identidad por parte del poder constituido desde la presidencia-gobierno-estado-nación-, condición ésta que también le aleja del pueblo relativo al gobierno.

"en el intercambio simbólico se convierte en un problema político, de lucha por ocupar espacios de emisión/recepción, por constituirse en interlocutor visible y voz audible" (Hopenhayn, 2002: 1) se produce esa asimetría que es el resultado de la voz y visibilidad que Chávez dio en el momento del intento de golpe de estado en 1992 y, por otro lado, la forma de presencia y permanencia de Chávez en el imaginario colectivo en sus apariciones diarias por radio y TV. Es, por decirlo de alguna manera, el propio poder político el responsable de la creación y puesta en circulación de los elementos culturales que constituyen el imaginario cultural y político en Venezuela. Una maquinaria comunicativa para construir los mensajes sobre la base de sus propias necesidades simbólicas, sobre la construcción de una identidad a la medida de las propias transformaciones culturales que van gestándose en el espacio público y ciudadano.

Como propone Hopenhayn (2002) la posesión de los medios de comunicación permite la creación de una plataforma de identidad. Eso es lo que ha hecho que el chavismo, poseer los mecanismos de producción y divulgación cultural, por diferentes vías, expropiaciones o no renovación de concesiones, con el único fin de desvirtuar a la oposición y, a la vez, estandarizar los signos del poder -el rojo, las camisetas rojas, la raza y sus tonos de piel 'originarios', las costumbres más arraigadas de 
la venezolanidad-, lo que "desanima a cualquier entusiasta del multiculturalismo" (Hopenhayn, 2002: 1).

Bajo la plataforma de identidad del chavismo se deja de ser ciudadano, en el sentido de ser depositario de un conjunto de derechos y deberes, y se pasa a ser un sujeto empoderado por su capacidad de demandar del Estado aquellos elementos para los que se le ha facultado desde la mediación, desde el aparato comunicativo creado por el gobierno-estado-nación que busca, con ese empoderamiento, un afianzamiento en el poder político-institucional que le dio legitimidad a esa identidad cultural y política.

Esta dialéctica amparada en la negación del otro y de lo otro se refuerza en la política comunicacional del gobierno de Chávez y hoy de Maduro. Se pretende acabar con el discurso opositor con el uso del lenguaje, de adjetivos calificativos y sustantivos peyorativos para referirse de modo simbólico al otro, a quien detenta el otro lado del discurso dialéctico. Considerar que este discurso dialéctico es nuevo y una creación del chavismo, debe remontarse a la propia historia de América Latina y el Caribe. Es una historia cuyas formas sociales se fundamentaron en la exclusión, en procurar hacer invisible al otro, tal y como se hizo en otros tiempos en los que la política estaba más cerca de las clases dominantes desde la tenencia del aparato productivo. Un vuelco completo es lo que se ha logrado. Las anteriormente clases dominantes son ahora las oprimidas y, las que en el pasado histórico lo fueron, ahora detentan el discurso cultural, la identidad política.

García Canclini se pregunta “¿Defender las identidades o globalizarnos?” (2000: 67). Podemos imaginar la respuesta del presidente Chávez. La globalización no es la salida, hay que defender las identidades originarias de América. En ese ámbito cultural, en lo que ha significado la expansión del marco político del chavismo hacia otros pueblos de América Latina, la propia constitución de Bolivia -aprobada bajo el actual gobierno de Evo Morales- plantea que ese país es una mezcla de culturas y un crisol que suma a los indígenas como una sola nación, como un solo pueblo, cuando en el propio ámbito de la cultura amerindia -y por citar un ejemplo- la constitución boliviana reconoce la diversidad cultural de sus pueblos originarios (Römer, 2009). La identidad venezolana después de la irrupción de Chávez pretende por una parte excluir al que de alguna manera fue dominante en el pasado. Blanco, rico, político, cercano a otras culturas, especialmente aquellas que pertenecen a los hemisferios norte y occidental. Por la otra, destacar la originalidad del pueblo base, del amerindio, de su fusión con el negro oprimido. Porque, las formas del poder que proporcionaban esa identidad al blanco provenían de que "no sólo se trataba de reverenciar adecuadamente (...) sino de destacar las diferentes artes que se poseían. Eran modos de hacerse buen ciudadano" (Römer, 2013: 241).

Chávez creó una plataforma de identidad cultural y política basada en diferentes esferas de comunicación. García Canclini lo apunta bien cuando considera que las esferas micropúblicas son laboratorios de comunicación que se fundamentan en grupos sociales pequeños como las comunidades de vecinos porque, al provenir de 
una cultura cotidiana adoptan una dimensión diferente entre el grupo y el grupo inmediatamente superior, el municipio, por ejemplo. La siguiente esfera de identidad es la mesoesfera pública que contempla al Estado-Nación en la que el debate ocurre en los medios de comunicación; $y$, finalmente, la esfera de lo macropúblico que está conformada por las agencias de noticias (Keane, 1985 en García Canclini, 2002).

Chávez fue capaz de crear las tres esferas de comunicación para el desarrollo de la identidad cultural que le diera amparo su identidad política. Impulsó los consejos comunales (micropúblicos), establecidos como formas de integración social y de reconocimiento colectivo. Grupos sociales con suficiente poder como para respaldar o endosar lo que los medios de comunicación al servicio de Chávez (mesoesfera pública) muestran y, para que no quedara fuera la fuerza comunicacional internacional, creó su propio canal de información, su agencia de noticias de influencia pancontinental: Telesur (macropúblico). Así, con un aparato de comunicación que abarcó todas als esferas sociales, el chavismo fue capaz de crear, desarrollar y sustentar toda una política de culturalización y generación de identidad en torno a la figura de Chávez y, es más, en torno al ámbito ideológico que lo sustenta: el socialismo del Siglo XXI.

\section{Conclusiones}

La nueva identidad cultural y política venezolana ha sido diseñada, impulsada y propugnada por el presidente Chávez. Es una identidad amparada en el uso de los medios de comunicación, en el conocimiento histórico de los resentimientos sociales coloniales, en el manejo de la política de alternancia del poder de los partidos políticos dominantes, así como del conocimiento de las corruptelas que se gestaron en torno al poder económico.

El conocimiento de coyuntura y el manejo de la opinión pública en torno a la creación de coyunturas propicias para la instauración ideológica, sumadas a esas necesarias reivindicaciones populares que puso en la palestra pública el presidente Chávez, así como el discurso repetido de combate contra la corrupción dándose un halo de moralidad al tomar el poder, hicieron, junto a esa política de comunicaciones y un entramado de apoyo social a través de las misiones, la creación y consolidación de la identidad cultural y política venezolana contemporánea: el chavismo. Así, la exclusión del otro -de aquel que detentó el poder económico, cultural, estético, social o político- hizo que los espacios discursivos que eran propios de las clases dominantes fuesen adoptados por el otro lado de la dialéctica discursiva: el chavismo.

De esa manera, la expresión chavista es clara: o se está con el poder y sus expresiones, o no se está y se es opositor. Y, el ser opositor no significa nada más que adoptar una posición ideológica diferente, sino que también se renuncia al aparato de comunicación que el chavismo ha creado. Ser opositor implica, además, adecuarse a nuevas condiciones sociales impuestas por la nueva identidad cultural y política. Así 
como también, considerarse parte del pueblo chavista, es asumir como propia toda esa ideología que emana desde el poder político. Se adopta una posición políticamente participante al hacerse parte del aparato comunicativo, se vincula el ciudadano directamente con el poder en lo estético, en lo cultural, en lo social, en lo político. Una identidad legitimada por los medios de comunicación, por las plataformas comunicativas que el presidente Chávez creó.

\section{Bibliografía}

ALTEZ, Yara (2003) Apuntes para un nuevo debate sobre identidad cultura, En: MATO, Daniel (coord.): Políticas de identidades y diferencias sociales en tiempos de globalización, pp. 79-95. FACES - UCV. Caracas.

CALDERA PIETRI, Juan José. (2007) El sobreseimiento de Chávez. http://rafaelcaldera.com/image/userfiles/image/libros_y_folletosRC_pdf/El_sobreseimiento_ de Chavez.pdf [27-10-2013]

CALDEVILLA DOMÍNGUEZ, David (2011): Las independencias americanas: historiografía, prensa e identidad criolla, en Revista Historia y Comunicación Social, Vol. 16, p. 13-31. Disponible en: http://revistas.ucm.es/index.php/HICS/ article/view/37147/35952 [10-09-2013].

CHÁVEZ FRÍAS, Hugo (1992): Intervención frente a los medios de comunicación luego del intento del golpe de Estado. Disponible en: http://www.youtube.com/ watch? $v=$ VBUo-pYeVfQ [1-11-2013]

CHÁVEZ FRÍAS, Hugo (1999): Discurso de Toma de Posesión, en Analítica.com. Disponible en: http://www.analitica.com/bitblioteca/hchavez/toma.asp. [15-082013]

EFE (26 de octubre de 2010) Conozca las expropiaciones y nacionalizaciones que ha realizado Chávez desde 2007, en Noticias24.com. Disponible en: http://economia. noticias24.com/noticia/38045/conozca-las-expropiaciones-y-nacionalizacionesque-ha-realizado-chavez-desde-2007/. [19-09-2013]

GARCÍA CANCLINI, Néstor (2000) Políticas culturales: de las identidades nacionales al espacio latinoamericano, En: GARCÍA CANCLINI, Néstor y MONETA, Carlos (coords.): Industrias Culturales en la Integración Latinoamericana. Grijalbo. México.

HOPENHAYN, Martín (2002) El reto de las identidades y la muticulturalidad, en Pensar Iberoamérica: Revista de Cultura. Disponible en: www.oel.es/pensariberoamerica/ric00a01.htm. [17-09-2013]

MATHEUS, Marjuli (08 de enero de 2012) Las 30 “Misiones” de Chávez, en Últimas Noticias. Disponible en: http://www.ultimasnoticias.com.ve/noticias/actualidad/ politica/las-30 - misiones - de-chavez.aspx. [10-07-2013]

MERCAL (2013). 10 aniversario Mercal: en el corazón del pueblo. Disponible en: http://www.mercal.gob.ve. [22-09-2013]

MOSONYI, Esteban Emilio (1981) Dialéctica de la Identidad Nacional, en SIC, Centro Gumilla, Abril, 1981, Vol. 44, N 434, pp. 157-160. Caracas. 
RÖMER PIERETTI, Max (2009) Constitución boliviana: ¿Reivindicaciones históricas o socialismo a la indígena? En: Razón y Palabra, No. 8, pp. 47-49.

RÖMER PIERETTI, Max (2013) Perfiles icónicos para la identidad venezolana desde la prensa del siglo XIX: la mirada de la revista El Cojo Ilustrado del centenario del mariscal Antonio José de Sucre, en JIMÉNEZ REDONDO, Juan Carlos y SAAVEDRA INAJARA, María (coords.): Tan iguales, tan diferentes. La Construcción de la identidad iberoamericana. Ediciones Encuentro. Madrid.

SEMPRÚN, Alfredo (1989) Carlos Andrés Pérez reitera la necesidad de una solución global al problema de la deuda. El País, 3 de febrero de 1989, pág. 27. [En línea] http://hemeroteca.abc.es/nav/Navigate.exe/hemeroteca/madrid/ abc/1989/02/03/02, [27-10-2013]

\section{El autor}

Max Römer Pieretti es Doctor en Ciencias de la Información-Periodismo por la Universidad de La Laguna (Tenerife-España, 1993) y Licenciado en Comunicación Audiovisual por la Universidad Católica Andrés Bello (Caracas-Venezuela, 1985).

Profesor e investigador inició su carrera académica en 1989. En 1991 se incorpora como profesor a la Universidad Católica Andrés Bello donde tuvo, entre otros cargos, el de Director de la Escuela de Comunicación Social (1997-2007).

En 2010 se suma al cuerpo docente de la Universidad Camilo José Cela y hoy es el Director del Grado de Comunicación Audiovisual y Coordinador de Investigación de la Facultad de Ciencias de la Comunicación. 